\title{
Achieving WHO target of HCV control in Hong Kong: challenges and strategies
}

\author{
Yudong Wang', Gregory Cheng ${ }^{1,2}$, George Lau ${ }^{1,3, *}$ \\ ${ }^{1}$ Humanity and Health Clinical Trial Center, Humanity \& Health Medical Group, Hong Kong SAR, China; \\ ${ }^{2}$ Faculty of Health Science, University of Macau, Macau SAR, China; \\ ${ }^{3}$ The Fifth Medical Center of Chinese PLA General Hospital, Beijing, China.
}

\begin{abstract}
With the introduction of effective directly acting antiviral agents (DAAs) therapy, control and elimination of hepatitis $\mathrm{C}$ virus (HCV) infection is becoming a feasible goal. In Hong Kong, HCV prevalence in general population is $0.3 \%-0.5 \%$ over the past decades. However, like other high-income areas/countries, high prevalence of HCV infection has been found in several population groups, such as people who inject drugs (PWID), patients undergoing dialysis, and human immunodeficiency virus infection and acquired immunodeficiency syndrome (HIV/ AIDS) patients. Based on the epidemiological study using data retrieved from the Hong Kong HCV Registry from January 2005 to March 2017, the estimated territory-wide diagnosis rate and treatment rate of HCV infection were only $50.9 \%$ and $12.4 \%$, respectively. Although these rates was comparable to many developed countries/areas, the performances remained substantially below $90 \%$ and $80 \%$, the 2030 targets proposed by World Health Organization (WHO). In recognition of the challenges, the Hong Kong Government set up the Steering Committee on Prevention and Control of Viral Hepatitis (SCVH) which formulated the Hong Kong Viral Hepatitis Action Plan 2020-2024. The Action Plan adopts four key strategies, as described in the WHO framework for global action, namely, awareness, surveillance, prevention and treatment. With the effective implementation of the Action Plan, especially in targeted screening of high-risk populations and more generalized use of the highly efficacious DAAs for all diagnosed HCV subjects, the goals of reducing HCV transmission and HCV-related morbidity and mortality can be achieved in Hong Kong by 2030.
\end{abstract}

Keywords: HCV, prevention, treatment, elimination, Hong Kong

\section{Introduction}

Hepatitis $\mathrm{C}$ virus $(\mathrm{HCV})$ is a small, enveloped, single stranded RNA virus identified in 1989 and is transmitted mainly through exposure to contaminated blood or blood products $(1,2)$. As one of the major causes of liver-related morbidity and mortality, including liver cirrhosis and hepatocellular carcinoma (HCC), chronic $\mathrm{HCV}$ infection is becoming an important public health burden, with around 71 million infections worldwide and at least 400,000 deaths per year (3-5). Currently, there is still no effective vaccine for the prevention of $\mathrm{HCV}$ infection (6).

Over the past dozen years, the mainstay treatment for patients with $\mathrm{HCV}$ infection was the combination of weekly subcutaneous injections of pegylated interferon (PegIFN) and daily oral ribavirin (RBV). This treatment required 24-72 weeks and was accompanied by a wide variety of side effects and less than $60 \%$ of patients can achieve the sustained virologic response (SVR) (79). The development of directly acting antiviral (DAA) agents has revolutionised HCV treatment since 2014. Compared to the PegIFN/RBV regimen, DAA therapy is of shorter duration (8-24 weeks) and achieves over $90 \%$ SVR rate. It is also well tolerated and suitable for patients with former contraindications to PegIFN/RBV therapy, such as patients with decompensated cirrhosis or significant comorbidities (10-12). The pan-oral, IFN-free DAAs regimens with or without RBV have recently been recommended as the first-line therapy for $\mathrm{HCV}$ infection in clinical practice guidelines endorsed by different academic societies (13-16).

Meanwhile, in the light of these more efficacious treatment options, the World Health Organization (WHO) proposed to eliminate $\mathrm{HCV}$ as a public health threat, targeting a diagnosis rate of $90 \%$ of total infections, a $90 \%$ decrease in new infections and a $65 \%$ decrease in liver-related mortality by 2030 as compared with the baseline in 2015 (17). To realize these targets, several significant barriers should be overcome, including knowledge and awareness of viral hepatitis, identification of undiagnosed individuals, linkage to 
continued care, and prevention of the occurrence of new cases or re-infection.

In this review, we summarize the current status of $\mathrm{HCV}$ epidemiology, diagnosis and treatment in Hong Kong, and outline the strategies formulated by the Hong Kong government for achieving the WHO goal of eliminating viral hepatitis as a major public health threat by 2030 .

\section{Epidemiology of HCV infection in Hong Kong}

\section{Prevalence of $\mathrm{HCV}$}

In contrast with high prevalence of hepatitis B virus (HBV) infection in Hong Kong, HCV infection is an uncommon occurrence among the local general population. One study of 382 individuals who attended a health exhibition in 1988 found that the prevalence of anti-HCV positivity was $0.5 \%$ (18). A communitybased, territory-wide epidemiological study recruited 10,256 participants from February 2015 to July 2016, and found that overall anti-HCV positivity was $0.5 \%$ and the prevalence of viraemic HCV infection was $0.3 \%$ (19). Meanwhile, data from new blood donors in Hong Kong Red Cross Blood Transfusion Service, a major source of HCV epidemiological information, showed that HCV prevalence in adolescents and young adults ranged between $0.03 \%$ and $0.11 \%$ since the implementation of anti-HCV screening in 1991 (Figure 1). Among 29,332 new blood donors screened in 2019, anti-HCV was more commonly detected in subjects aged over 40 years as compared to those aged below 40 years $(0.19 \%$ vs. $0.04 \%)$, and males were more commonly infected than females $(0.10 \%$ vs. $0.05 \%)(20)$.

Before $1990 \mathrm{~s}, \mathrm{HCV}$ was infected mainly through transfusion with contaminated blood or blood products. With the introduction and implementation of anti-HCV screening for blood donations since 1991, the risk of transfusion-transmitted HCV infections has decreased to a very low level in Hong Kong (21). Transfusiontransmitted HCV infections are mainly found in patients requiring frequent blood or blood product transfusions, such as haemophilia patients. In high-income areas/ countries, most HCV transmission has been found among PWID (22). From local studies published in the early 1990s, it was shown that anti-HCV was more commonly found in PWID (66.8\%) and haemodialysis patients (4.6\%) (18). An HCV seroprevalence study conducted in 2006 in methadone clinics, showed a $85 \%$ prevalence rate of anti-HCV seropositivity in this community (23). More recent studies involving PWID recruited at their gathering places also gave a similar figure of anti-HCV prevalence of $81.7 \%$ among 622 subjects in 2011 and $76.4 \%$ among 664 subjects in 2014, respectively $(24,25)$. Among these subjects, injection duration, current or recent injections, sharing of injecting needles and concomitant use of other drugs, such as midazolam, were identified as the independent factors associated with $\mathrm{HCV}$ infection. In the New Life New Liver Project conducted between 2009 and $2018,73.4 \%$ of 365 subjects participating in a targeted screening and assessment program for ex-PWID, were found to be anti-HCV positive (26).

HIV/AIDS patients are another population disproportionately affected by $\mathrm{HCV}$ infection in Hong Kong. Among 4416 new HIV/AIDS patients attending the Integrated Treatment Centre of Centre for Health Protection from 2000 to 2019,385 (8.7\%) tested positive for anti-HCV, and the prevalence rate appeared to be higher in male than female patients $(9.4 \% \mathrm{vs} .4 .1 \%)$ (20). HIV/HCV coinfection was found in $1.5-6.0 \%$ of HIV/AIDS patients infected through sexual contact, as compared with $97 \%$ of those patients infected through drug injection. Among those heterosexual HIV-infected

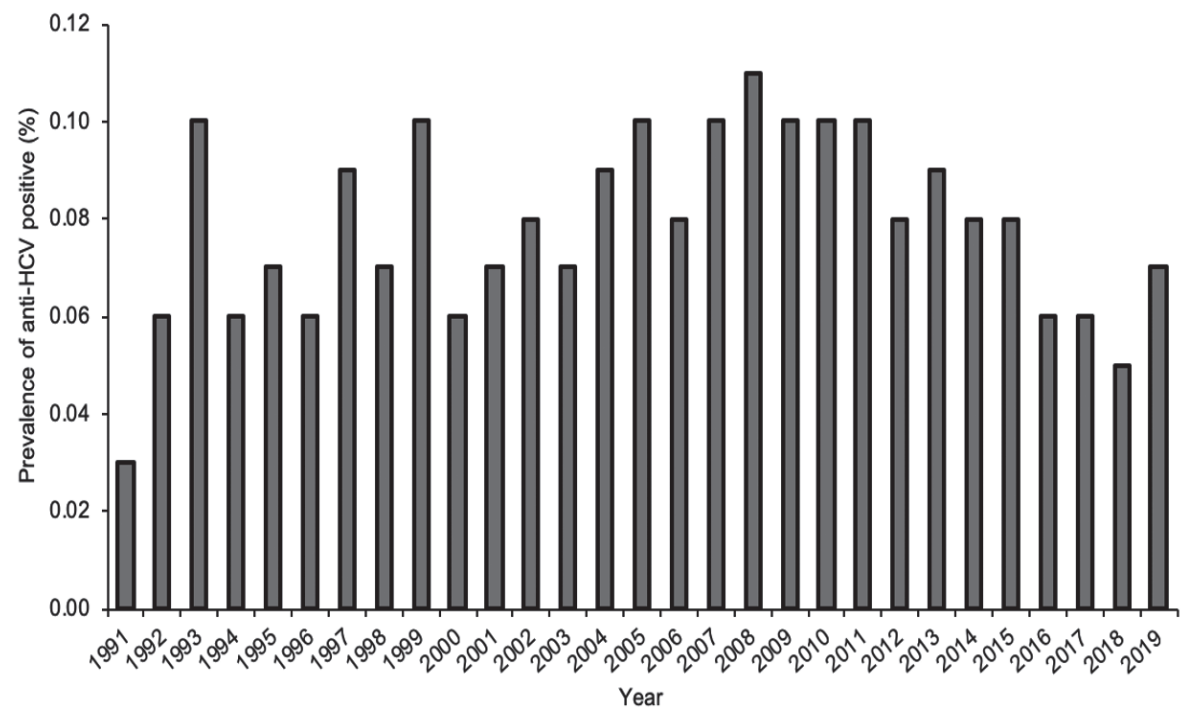

Figure 1. Prevalence of anti-HCV positive in new blood donors from 1991 to 2019 in Hong Kong (Date source: Hong Kong Red Cross Blood Transfusion Service, Hong Kong Special Administrative Region, China). 
male patients without history of intravenous drug use, only $2.5 \%$ were anti-HCV positive (20).

\section{HCV Genotypes}

HCV is an enveloped, positive-strand RNA virus with extensive genetic heterogeneity, and has been classified into 7 major genotypes and over 75 subtypes with broad distribution in different geographical distributions (27). In contrast to western countries/regions where $\mathrm{HCV}$ genotype $1 \mathrm{a}$ is the most prevalent, $\mathrm{HCV}$ infections in Hong Kong are predominately caused by genotype $1 \mathrm{~b}$ and 6a (28). In an early study involving 212 viraemic blood donors from 1991 to 1994, genotype $1 \mathrm{~b}$ and 6 were detected in $58.8 \%$ and $27.0 \%$, respectively (29). In a recent comprehensive population-based epidemiological study, the prevalent HCV genotype was genotype 1 (48.8\%), followed by genotype $6(33.6 \%)$, genotype 3 (10.8\%) and genotype $2(3.2 \%)$ among 2699 anti-HCV positive patients from all public hospitals in Hong Kong between January 2005 and March 2017 (30). While in $\mathrm{HIV} / \mathrm{HCV}$ co-infected patients, genotype 3 is the most common $(27.2 \%)$, followed by genotype 1a (14.8\%), genotype $1 \mathrm{~b}(11.1 \%)$ and genotype $6(11.1 \%)(30)$.

\section{Current challenges and strategies in controlling $\mathrm{HCV}$ infection in Hong Kong}

Although much has been done to prevent and control $\mathrm{HCV}$ infection and keep the prevalence rate low over the past decades in Hong Kong, a higher number of acute HCV infections had been reported annually in the past ten years as compared with the decade before (Figure 2) (20). Hong Kong is an international city with high population mobility, and people may get $\mathrm{HCV}$ infection in other countries/areas where effective screening and control of $\mathrm{HCV}$ infection might not have been implemented and achieved (21). Certain misconceptions of HCV infection are also widespread in the local community, such as the disease cannot be cured, or the disease is relatively benign because most of the patients with HCV infection are asymptomatic in the early phase. A retrospective analysis of untreated HCV-infected patients from 2000 to 2009 found that $31.9 \%$ of 138 patients declined treatment due to patients' preference (31). Based on the recent epidemiological study using data retrieved from the Hong Kong HCV Registry which covers up $94 \%$ of all secondary and tertiary care services in Hong Kong, a total of 11,309 patients who tested positive for anti-HCV were identified from January 2005 to March 2017 (30). Among these patients, only 2201 were found to have received antiviral treatment. Given a population of 7.4 million people and assuming a prevalence of $0.3 \% \mathrm{HCV}$ infection with a viremic rate of $80 \%$ in Hong Kong, the estimated territory-wide diagnosis rate and treatment rate were only $50.9 \%$ and $12.4 \%$, respectively. Although these rates were comparable to many developed countries/ areas, the performance remained substantially below the 2030 targets of $90 \%$ and $80 \%$, proposed by WHO.

Based on the hepatitis elimination initiative of the WHO, it is critical to identify HCV infected individuals to start antiviral therapy, avoid further transmission and the occurrence of new cases (4). Traditionally, HCV screening starts with testing the antibodies against $\mathrm{HCV}$ (anti-HCV) with immunoassay and then viral load quantitation using a polymerase chain reaction-based assay for subjects with positive anti-HCV results. This two-step process requires multiple visits and may take several days or weeks, leading to delayed diagnosis and increased risk of losing the patient to follow-up treatment (32). With the development of point-of-care

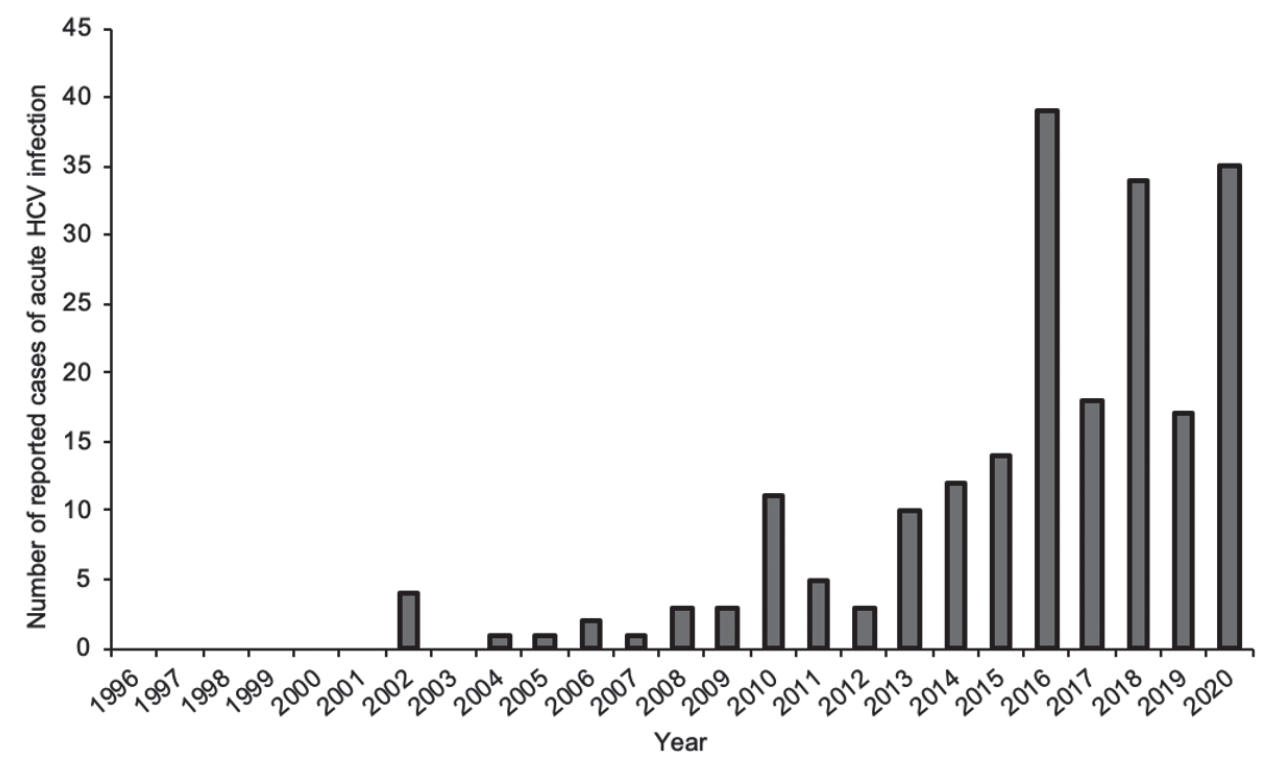

Figure 2. Number of reported cases of acute HCV infection from 1996 to 2020 in Hong Kong (Date source: Centre for Health Protection, Department of Health, Hong Kong Special Administrative Region, China). 
(POC) and rapid diagnostic tests (RDT) which can offer results in minutes, rapid screening, confirmation of diagnosis and treatment initiation in the same clinic visit are possible nowadays.

Before 2014, PegIFN/RBV therapy was the mainstay treatment of patients with HCV infection. However, many patients with HCV infection declined the treatment due to the long treatment duration and associated adverse effects. It was noted that of 1,533 patients in consideration for PegIFN/RBV therapy, $16.1 \%$ refused this regimen while $17.2 \%$ did not get the treatment due to contraindication (30). With the development of DAAs, the treatment paradigm for HCV infection has been revolutionised since 2014 . In comparison with traditional IFN-based therapy, DAAs are associated with high SVR (>90\%), shorter treatment duration (8-24 weeks), and much fewer side-effects. However, the high price of DAA therapy may prohibit its widespread use (33-35). In Hong Kong, due to a limited health-care budget and lack of comprehensive insurance coverage schemes, DAAs are not universally prescribed for every patient with $\mathrm{HCV}$ infection. Risk stratification is the strategy adopted by the Hospital Authority to prioritize those patients with advanced liver fibrosis (F3) or cirrhosis (F4), to receive subsidized DAA treatment.

In recognition of these service gaps, the Hong Kong Government announced in the 2017 Policy Address setting up a steering committee to formulate strategies to prevent and control viral hepatitis effectively. After reviewing local and international trends and new developments in the prevention and control of viral hepatitis, the committee formulated the Hong Kong Viral Hepatitis Action Plan 2020-2024 in October 2020, providing a detailed strategic process for controlling $\mathrm{HCV}$ infection and reducing the public health burden in Hong Kong (36). The Action Plan adopts four key strategies, as described in the WHO framework for global action, namely, awareness, surveillance, prevention and treatment, to eliminate $\mathrm{HCV}$ infection in Hong Kong (Table 1).

\section{Awareness}

Lack of knowledge and awareness about HCV infection probably contributes to continued HCV transmission and missed prevention, early diagnosis and medical care opportunities (37). As described in the Action Plan, $\mathrm{VHCO}$ has been promoting public awareness through various channels, including, telephone hotline, internet, printed materials, health talks for the public, etc. A website (www.hepatitis.gov.hk) has been revamped to provide essential and up-to-date information on viral hepatitis by VHCO in early 2020. Roving exhibitions on viral hepatitis with different yearly themes of the awareness campaign are held on World Hepatitis Day each year. Meanwhile, professional training programs with the knowledge-attitude-practice (KAP) assessment for healthcare workers of different specialties are conducted in phases. Education on safe injection and safer sex practices for prevention of $\mathrm{HCV}$ infection is being integrated with the HIV prevention program, while standardized training and education materials on $\mathrm{HCV}$ infection for service providers of PWID is also developed. More importantly, the awareness campaign should emphasize that HCV is not a benign disease, which can potentially lead to liver cancer and liver failure, but the disease is curable nowadays.

\section{Surveillance}

As indicated by the Action Plan, the present surveillance system has some limitations, including under-reporting, seroprevalence data limited to specific subgroups, and artificial variation in incidence. A set of local indicators for monitoring and evaluation of $\mathrm{HCV}$ elimination strategies, including the prevalence of chronic HCV infection, people living with HCV diagnosed, treatment initiation and cure for patients with $\mathrm{HCV}$ infection, incidence of $\mathrm{HCV}$ infection, and deaths attributable to HCV infection, have been adopted to enhance the current surveillance system. Meanwhile, the Population Health Survey (PHS), a territory-wide survey with

Table 1. The action plan for eliminating HCV epidemic in Hong Kong

\begin{tabular}{ll}
\hline Key strategies & \multicolumn{1}{c}{ Contents } \\
\hline Awareness & - Awareness campaign for the general population \\
& - Professional training for healthcare workers \\
& - Education targeting at-risk populations, patients and their service providers \\
& - Building a supportive environment \\
& - Ongoing surveillance from notification system for acute and chronic HCV infection \\
Surveillance & - Development of local indicators for monitoring and evaluation of the HCV elimination strategies \\
& - Reduction of risk and disease burden in vulnerable populations \\
Prevention & - Prevention of healthcare-related transmission of HCV \\
Treatment & - Promotion of HCV testing in people who inject drugs \\
& - Micro-elimination of HCV in targeted populations \\
& - Expansion of access to DAAs for HCV \\
\hline
\end{tabular}


two components, namely household questionnaire survey and health examination, is being conducted during 2020-2021. It will cover the land-based noninstitutional population aged 15 or above for the household questionnaire survey and a subsample of respondents aged between 15 and 84 for health examination. It will provide a representative and detailed analysis of the latest prevalence of chronic $\mathrm{HCV}$ infection in the general population, as well as the proportion of patients with chronic HCV infection who have been diagnosed, treated and cured. Clinical data from Health Authority will be the main data source for treatment initiation and cure for HCV patients as the majority of local populations are receiving outpatient and inpatient services for viral hepatitis in public hospitals of the Health Authority. Hopefully, this will significantly improve the $12 \% \mathrm{HCV}$ treatment rate among diagnosed subjects reported in the territory-wide population-based study of chronic $\mathrm{HCV}$ infections in 2018 (30).

\section{Prevention}

Due to lack of a safe and effective vaccine, controlling practices known to spread HCV and curing patients with $\mathrm{HCV}$ infection should be taken as the prevention measures. In Hong Kong, the current blood safety strategies based on voluntary blood donations and quality-assured screening program can prevent transmission of HCV effectively. Patients potentially infected with HCV through contaminated blood or blood procedures before the implementation of antiHCV screening for blood donors in 1991 are being traced, investigated and treated by Health Authority. Meanwhile, infection control training on Standard Precautions, such as aseptic technique, proper sharps handling and management of needlestick injury or mucosal contact, is being provided to healthcare workers on a regular basis, with an aim to reduce their chance of acquiring or passing on infections of $\mathrm{HCV}$, through occupational exposure. On the other hand, condom programming and a harm reduction approach are needed to be intensified due to the emergence of sexually acquired HCV infection in HIV-positive MSM. The possibility that sexually acquired HCV crosses to HIV-negative MSM should also be scrutinized.

\section{Treatment}

Curing chronic HCV infection has been demonstrated to have an immense benefit not only for the patients but also society (38-40). With the gradual expansion of DAA therapy from patients with advanced fibrosis or cirrhosis who were contraindicated or intolerant to conventional PegIFN/RBV therapy to all HCV patients regardless of their disease severity in the fourth quarter of 2021 stated in the Action Plan, the remaining obstacles to treatment are identification of undiagnosed $\mathrm{HCV}$ patients and linkage to continued care and treatment. Universal screening for anti-HCV is not costeffective due to the low prevalence of $\mathrm{HCV}$ infection in Hong Kong. However, several population groups with high prevalence of $\mathrm{HCV}$ infection, such as patients undergoing dialysis and HIV-positive patients, will be targeted for screening and treatment to achieve microelimination in these well-defined populations. PWID is another priority population for enhancing prevention, testing, linkage to care, treatment and follow-up care. A policy initiative to promote $\mathrm{HCV}$ screening and treatment in PWID, who are attending methadone clinics or are under custody of Correctional Services Department, has been established. Perhaps, point-ofcare and rapid diagnostic tests can be offered to PWID attending methadone clinics along with educational information about $\mathrm{HCV}$ transmission through contaminated injection equipment. Currently, there are around 5,200 people registered with methadone clinics with an average 3,900 daily attendance. A pilot program involving selected methadone clinics is being carried out to test the feasibility and assess the acceptance of HCV testing among PWID. The information gained from the pilot program can also help better characterize the barriers to $\mathrm{HCV}$ testing and care, and devise strategies to overcome them.

The implementation of the above Action Plan will be monitored and evaluated regularly through different targets and indicators to drive progress towards the WHO 2030 goals of eliminating HCV infection in Hong Kong.

\section{Conclusions}

In Hong Kong, the estimated HCV prevalence in general population is $0.3 \%-0.5 \%$, prevailing in several specific populations, including PWID, patients undergoing dialysis and HIV/AIDS patients. However, our territory-wide diagnosis rate and treatment rate are still substantially below the 2030 WHO targets of viral hepatitis elimination. To realize the elimination target, four key strategies including awareness, surveillance, prevention and treatment have been adopted in the Hong Kong Viral Hepatitis Action Plan 2020-2024. With the implementation of the Action Plan, especially in targeted screening approaches on high-risk populations and more generalized use of the highly efficacious DAAs for all diagnosed HCV subjects, the goals of reducing $\mathrm{HCV}$ transmission and HCV-related morbidity and mortality to the WHO targets can be achieved in Hong Kong by 2030.

\section{Funding: None.}

Conflict of Interest: The authors have no conflicts of interest to disclose. 


\section{References}

1. Choo QL, Kuo G, Weiner AJ, Overby LR, Bradley DW, Houghton M. Isolation of a cDNA clone derived from a blood-borne non-A, non-B viral hepatitis genome. Science. 1989; 244:359-362.

2. Houghton M. Discovery of the hepatitis C virus. Liver Int. 2009; 29 Suppl 1:82-88.

3. Stanaway JD, Flaxman AD, Naghavi M, et al. The global burden of viral hepatitis from 1990 to 2013: findings from the Global Burden of Disease Study 2013. Lancet. 2016; 388:1081-1088.

4. World Health Organization. Global Hepatitis Report 2017. https://www.who.int/publications-detail-redirect/ global-hepatitis-report-2017 (accessed May 30, 2021).

5. Polaris Observatory HCV Collaborators. Global prevalence and genotype distribution of hepatitis $\mathrm{C}$ virus infection in 2015: a modelling study. Lancet Gastroenterol Hepatol. 2017; 2:161-176.

6. Roger S, Ducancelle A, Le Guillou-Guillemette H, Gaudy C, Lunel F. HCV virology and diagnosis. Clin Res Hepatol Gastroenterol. 2021; 45:101626.

7. McHutchison JG, Gordon SC, Schiff ER, Shiffman ML, Lee WM, Rustgi VK, Goodman ZD, Ling MH, Cort S, Albrecht JK. Interferon alfa-2b alone or in combination with ribavirin as initial treatment for chronic hepatitis $\mathrm{C}$. Hepatitis Interventional Therapy Group. N Engl J Med. 1998; 339:1485-1492.

8. Fried MW, Shiffman ML, Reddy KR, Smith C, Marinos G, Gonçales FL Jr, Häussinger D, Diago M, Carosi G, Dhumeaux D, Craxi A, Lin A, Hoffman J, Yu J. Peginterferon alfa-2a plus ribavirin for chronic hepatitis C virus infection. N Engl J Med. 2002; 347:975-982.

9. Manns MP, Wedemeyer H, Cornberg M. Treating viral hepatitis C: efficacy, side effects, and complications. Gut. 2006; 55:1350-1359.

10. Schinazi R, Halfon P, Marcellin P, Asselah T. HCV direct-acting antiviral agents: the best interferon-free combinations. Liver Int. 2014; 34 Suppl 1:69-78.

11. Ji D, Chen GF, Wang C, Wang YD, Shao Q, Li B, Zhao J, You SL, Hu JH, Liu JL, Niu XX, Chen J, Lu L, Wu V, Lau G. Twelve-week ribavirin-free direct-acting antivirals for treatment-experienced Chinese with HCV genotype $1 \mathrm{~b}$ infection including cirrhotic patients. Hepatol Int. 2016; 10:789-798.

12. Martinello M, Hajarizadeh B, Grebely J, Dore GJ, Matthews GV. Management of acute HCV infection in the era of direct-acting antiviral therapy. Nat Rev Gastroenterol Hepatol. 2018; 15:412-424.

13. Omata M, Kanda T, Wei L, et al. APASL consensus statements and recommendation on treatment of hepatitis C. Hepatol Int. 2016; 10:702-726.

14. Kanda T, Lau GK, Wei L, et al. APASL clinical practice recommendation: how to treat $\mathrm{HCV}$-infected patients with renal impairment? Hepatol Int. 2019; 13:103-109.

15. Ghany MG, Morgan TR; AASLD-IDSA Hepatitis C Guidance Panel. Hepatitis C Guidance 2019 Update: American Association for the Study of Liver DiseasesInfectious Diseases Society of America Recommendations for Testing, Managing, and Treating Hepatitis C Virus Infection. Hepatology. 2020; 71:686-721.

16. European Association for the Study of the Liver. EASL recommendations on treatment of hepatitis C: Final update of the series. J Hepatol. 2020; 73:1170-1218.

17. World Health Organization. Combating hepatitis B and
C to reach elimination by 2030. Published on May 2016. https://apps.who.int/iris/bitstream/handle/10665/206453/ WHO_HIV_2016.04_eng.pdf\%3bjsessionid\%3d4BD913 $237991690 \bar{D}$ E2A6A6FDE7DFD 5A8\%3fsequence\%3d1. (accessed May 5, 2021).

18. Chan GC, Lim W, Yeoh EK. Prevalence of hepatitis C infection in Hong Kong. J Gastroenterol Hepatol. 1992; 7:117-120.

19. Liu KSH, Seto WK, Lau EHY, Wong DK, Lam YF, Cheung KS, Mak LY, Ko KL, To WP, Law MWK, Wu JT, Lai CL, Yuen MF. A territorywide prevalence study on blood-borne and enteric viral hepatitis in Hong Kong. J Infect Dis. 2019; 219:1924-1933.

20. Viral Hepatitis Control Office, Department of Health, the Government of the Hong Kong Special Administrative Region. Surveillance of viral hepatitis in Hong Kong - 2019 Report. https://www.hepatitis.gov.hk/tc_chi/ document_cabinet/files/hepsurv19.pdf (accessed May 5, 2021).

21. Wong NS, Lee CK, Ng SC, Wong HK, Chan DPC, Lee SS. Prevalence of hepatitis $\mathrm{C}$ infection and its associated factors in healthy adults without identifiable route of transmission. J Viral Hepat. 2018; 25:161-170.

22. Cooke GS, Andrieux-Meyer I, Applegate TL, et al. Accelerating the elimination of viral hepatitis: a Lancet Gastroenterology \& Hepatology Commission. Lancet Gastroenterol Hepatol. 2019; 4:135-184.

23. Lee KC, Lim WW, Lee SS. High prevalence of HCV in a cohort of injectors on methadone substitution treatment. J Clin Virol. 2008; 41:297-300.

24. Wong NS, Chan PC, Lee SS, Lee SL, Lee CK. A multilevel approach for assessing the variability of hepatitis $\mathrm{C}$ prevalence in injection drug users by their gathering places. Int J Infect Dis. 2013; 17:e193-198.

25. Chan DP, Lee KC, Lee SS, Tan TY. Community-based molecular epidemiology study of hepatitis C virus infection in injection drug users. Hong Kong Med J. 2017; 23 Suppl 5:27-30.

26. Wong GL, Chan HL, Loo CK, Hui YT, Fung JY, Cheung D, Chung C, Chim AM, Wong VW; Hong Kong Association for the Study of Liver Diseases (HKASLD). Change in treatment paradigm in people who previously injected drugs with chronic hepatitis $\mathrm{C}$ in the era of direct-acting antiviral therapy. J Gastroenterol Hepatol. 2019; 34:1641-1647.

27. Bukh J. The history of hepatitis C virus (HCV): Basic research reveals unique features in phylogeny, evolution and the viral life cycle with new perspectives for epidemic control. J Hepatol. 2016; 65:S2-S21.

28. Messina JP, Humphreys I, Flaxman A, Brown A, Cooke GS, Pybus OG, Barnes E. Global distribution and prevalence of hepatitis $\mathrm{C}$ virus genotypes. Hepatology. 2015; 61:77-87.

29. Prescott LE, Simmonds P, Lai CL, Chan NK, Pike I, Yap PL, Lin CK. Detection and clinical features of hepatitis $\mathrm{C}$ virus type 6 infections in blood donors from Hong Kong. J Med Virol. 1996; 50:168-175.

30. Hui YT, Wong GLH, Fung JYY, et al. Territory-wide population-based study of chronic hepatitis $\mathrm{C}$ infection and implications for hepatitis elimination in Hong Kong. Liver Int. 2018; 38:1911-1919.

31. Yan KK, Wong GL, Wong VW, Chan HL. Rate and factors affecting treatment uptake of patients with chronic hepatitis C in a tertiary referral hospital. Dig Dis Sci. 2010; 55:3541-3547. 
32. Patel AA, Bui A, Prohl E, Bhattacharya D, Wang S, Branch AD, Perumalswami PV. Innovations in hepatitis C screening and treatment. Hepatol Commun. 2020; 5:371-386.

33. Chen GF, Wei L, Chen J, et al. Will sofosbuvir/ledipasvir (harvoni) be cost-effective and affordable for Chinese patients infected with hepatitis $\mathrm{C}$ virus? An economic analysis using real-world data. PLoS One. 2016; $1: \mathrm{e} 0155934$

34. Lau G. Shortening HCV therapy: science meets public health. Lancet Gastroenterol Hepatol. 2017; 2:771-772.

35. Thomas DL. Global elimination of chronic hepatitis. N Engl J Med. 2019; 380:2041-2050.

36. The Government of the Hong Kong Special Administrative Region. Hong Kong Viral Hepatitis Action Plan: 2020-2024. https://www.hepatitis.gov.hk/doc/action_ plan/Action\%20Plan_Full\%20Version_PDF_en.p $\overline{d f}$ (accessed May 5, 2021).

37. McLeod A, Cullen BL, Hutchinson SJ, Roy KM, Dillon JF, Stewart EA, Goldberg DJ. Limited impact of awareness-raising campaigns on hepatitis $\mathrm{C}$ testing practices among general practitioners. J Viral Hepat. 2017; 24:944-954.

38. Butt AA, Yan P, Shaikh OS, Lo Re V 3rd, Abou-Samra $\mathrm{AB}$, Sherman KE. Treatment of $\mathrm{HCV}$ reduces viral hepatitis-associated liver-related mortality in patients: An ERCHIVES study. J Hepatol. 2020; 73:277-284.

39. Butt AA, Yan P, Aslam S, Shaikh OS, Abou-Samra AB. Hepatitis $\mathrm{C}$ virus $(\mathrm{HCV})$ treatment with directly acting agents reduces the risk of incident diabetes: Results from electronically retrieved cohort of HCV infected veterans (ERCHIVES). Clin Infect Dis. 2020; 70:1153-1160.

40. Evon DM, Kim HP, Edwards A, Carda-Auten J, Reeve BB, Golin CE, Fried MW. "If I get cured, my whole quality of life will change": Patients' anticipated and actualized benefits following cure from chronic hepatitis $\mathrm{C}$. Dig Dis Sci. 2021. doi: 10.1007/s10620-021-06829-2.

Received June 18, 2021; Revised July 26, 2021; Accepted August 3, 2021.

Released online in J-STAGE as advance publication August 13, 2021.

*Address correspondence to:

George Lau, Humanity and Health Clinical Trial Center, Humanity \& Health Medical Group, No.9 Queen's Road Central, Central, Hong Kong SAR, China.

E-mail: gkklau@hnhmgl.com,gkklau@netvigator.com 